\title{
Financial ratios and the probabilistic prediction of bankruptcy among Malaysian civil servants
}

\begin{abstract}
The rising debt problem and bankruptcy among civil servants in this country is worrying. To what extent this problem is contributed by financial ratios is not empirically assured. Financial ratios and bankruptcy are two aspects that are wherefore related with one another that have received major consideration from scholars and financial advisor. Financial ratios can affect an individual, team and also organization either directly or indirectly. Changes in civil servant's financial ratios whether they achieved the minimum requirement by fulfilling only one out of three financial ratios (liquidity ratio, solvency ratio and consumer debt ratio) will affect the bankruptcy probability among them. The purpose of this study is to predict the bankruptcy probability of civil servants based on their financial ratio as a tool of objective measurement. A total of 399 civil servants from five randomly selected ministries responded to the e-survey (email based) using multistage cluster sampling technique. The results identified that around 20 out of 399 civil servants did not fulfill any of the financial ratio requirement and these are the civil servants who face higher chances of becoming bankrupt in five years' time. Apart from that, the findings of financial ratio in this study were considered fairly stable since 95 percent of the civil servants achieved the minimum requirement by fulfilling only one out of three financial ratios. It was also shown that five percent of the civil servants were identified to have bankruptcy probability. Thus, proper action should be taken through financial training, education and literacy in order to prevent unwanted scenarios in the future. Consequently, findings of this study may be used as basis to reduce financial problems and bankruptcy among Malaysian civil servants.
\end{abstract}

Keyword: Bankruptcy probability; Financial ratio; Liquidity ratio; Solvency ratio; Consumer debt ratio 